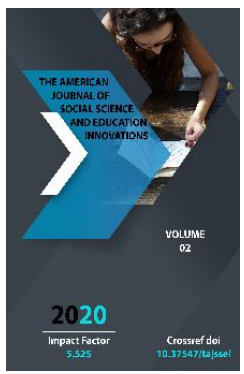

Journal Website: http://usajournalshub.c om/index,php/tajssei

Copyright: Original content from this work may be used under the terms of the creative commons attributes 4.0 licence.

\section{Use Of Innovative Methods In Teaching HIV / AIDS In Valeology}

Dilfuzakhon Adkhamovna Ibragimova

Senior Lecturer, Department Of Biology Teaching Methods, Kokand State Pedagogical Institute, Uzbekistan

Ranokhon Nabijanovna Muminova

Associate Professor, Department Of Biology Teaching Methods, Kokand State Pedagogical Institute, Uzbekistan

\title{
ABSTRACT
}

This article provides information on HIV / AIDS, ways of transmitting the virus, among the population, youth, schoolchildren, college students, institutes, improving medical culture and maintaining your health. When HIV viruses enter the human body, they infect T-helper lymphocytes. As they spread, they destroy lymphocytes, which actually paralyzes the functioning of the immune system. Also, conducting classes on the topic of HIV / AIDS, introducing new educational technologies and conducting innovative methods.

\section{KEYWORDS}

AIDS, HIV, drug addict, ventral infection, antigen, donor, retrovirus, Kaposchi's sarcoma, helpers, Tlymphocytitis, retrovirus, ERASMUS +, MODEHed.

\section{INTRODUCTION}

Nowadays, the study and analysis of the organizational and legal framework of the educational process in higher education institutions is one of the most important and urgent tasks. Organizational legal documents such as education legislation, normative legal 
acts, including decrees, orders, resolutions and orders, are used in the organization of the educational process of educational requirements of higher education institutions. Today, the term AIDS refers to the final stage of the disease. The process from the time of HIV infection until the first symptoms of AIDS appear is understood as HIV infection. An HIVinfected person is called an HIV carrier. Thus, HIV and AIDS are two concepts of the same disease AIDS is a disease that today is one of the global problems. This disease is widespread on earth and has not yet been cured.

Within the framework of the European Union's international program ERASMUS + "MODEHed - Modernization of Medical Science in Universities" project, based on foreign experience in teaching the subject "Fundamentals of HIV / AIDS" in the field of Valeology, classes are held in accordance with our mentality.

\section{MAIN PART}

HIV is the virus that causes AIDS, and this is the initial stage of this process. This virus weakens the human immune system, and eventually the body becomes unstable, unable to defend itself against even simple inflammatory diseases. There is no cure for this disease, which ultimately ends in tragic death.

Sources of HIV infection are infected patients and carriers of the virus because the virus is constantly circulating in their blood. The HIV virus is present not only in the blood but also primarily in semen and menstrual secretions, as well as in the secretions of the vaginal glands. In addition, HIV is present in breast milk, saliva, tears and gray matter fluid of the spinal cord, various tissues, sweat and urine. The most dangerous are the secretions of blood, semen and vagina, from which enough viruses have been detected to transmit the infection.

In the early stages of the diagnosis of AIDS, the disease is most prevalent in those who belong to a high-risk group of the population drug addicts, immoral people with congenital hemophilia. HIV is transmitted in ways specific to other retroviruses, i.e. vertically from mother to child and horizontally through sexual contact. It can also be transmitted parenterally (at the time of injection). Also, the biological fluid of an HIV-infected person can become contaminated even if it gets on the slightly damaged mucous membranes and skin of a healthy person.

The AIDS virus is resistant and is killed by boiling in water for 10 minutes. Special disinfectants can also be used. Alcohol does not kill HIV.

Routes of transmission of the AIDS virus:

- when infected blood is transfused into a healthy person;

- Through sexual contact with an HIVinfected patient:

- $\quad$ from an infected mother to her child during pregnancy, childbirth and breastfeeding;

- When using contaminated syringes.

- The clinical development of AIDS is divided into several stages:

The incubation period of the disease can last from 2-3 weeks to 1-2 months and, according to some data, up to 3-5 years.

1. The period before the onset of the disease, the latent period:

2. Acute advanced period of the disease.

3. Disease completion period.

The clinic of AIDS is characterized by symptoms of various opportunistic infections as well as malignant tumors. The first symptoms of AIDS appear before the obvious symptoms appear. The first symptoms are 
characterized by fever, diarrhea, lymphadenopathy, nausea, anemia, depression, the development of various purulent diseases of the skin and mucous membranes, and the suffering of the patient. Dryness of the patient, weight loss, sweating, as well as enlargement of the lymph nodes is the first signs of AIDS. When the AIDS virus enters the human body, T-lymphocytes have a detrimental effect on the helpers, resulting in a decrease in the activity of the T-helpers and then their death. It is known that $T$ lymphocytes are helpers - the human body plays an important role in the immune system. T-lymphocytes are helpers and cause a state of immunodeficiency in the body. The immune system of a healthy organism is a very complex and reliable means of protection of malignant tumor (cancer) cells, while maintaining the cells of various microbes, viruses, fungi and simple single-celled animals in the environment and in humans. It has been suggested that T-lymphocytes and helpers play a crucial role in the functioning of this immune system. HIV attacks the same Tlymphocyte helpers, infecting them and causing a state of immune deficiency in the body. As a result, previously undamaged saprophytic microorganisms attack and cause the development of various diseases. Similarly, cancer cells that have not been able to multiply before will begin to multiply rapidly under such favorable conditions. When HIV enters a T-lymphocyte, it becomes one with the cell. T-lymphocytes helper proteins synthesize proteins, and new young viruses emerge from these proteins. Thus, Thelpers serve the virus. The number of $T$ lymphocytes in the body decreases, the activity of the rest decreases.

This is the essence of the immune crisis that occurs in the human body with AIDS. Laboratory diagnosis is important in the diagnosis of AIDS. Among them: enzymelinked immunosorbentassay;

radioimmunoprecipitateanalysis;

radioimmunoprecipitatemethod;

immunoglobulin analysis is more commonly used and helps to make a diagnosis. Blood serum or plasma is taken as a material to detect antibodies to HIV, but recently the type of biological materials has been increasing. Within laboratory analysis is mainly immunoenzyme assay (IEA). HIV infection is continued by special methods. A medical examination to detect HIV infection is divided into mandatory and voluntary medical examination. The group of mandatory medical examinations for HIV testing includes:

- Blood, serum and other biological fluids, tissue donors;

- Individuals belonging to the "Risk Group" who are at high risk of contracting HIV / AIDS;

- Drugs that inject drugs into a vein (when detected and then 2 times a year);

- Homosexuals (when detected and then 2 times a year);

- Irregular, multiple sexual partners (once a year);

- When infected with sexually transmitted diseases (when detected and then once a year).

- People working with HIV, people living with HIV,

- Those involved in the diagnosis, treatment and direct care of AIDS patients (at the time of employment and once a year);

- Patients with clinical indications;

- Fever for more than a month;

- Diarrhea lasting more than a month;

- Unexplained loss of $10 \%$ or more of body weight;

- Lymphadenopathy lasting more than three months; 
- Chronic and recurrent pneumonia or ineffective treatment;

- Diseases that do not result in chronic inflammation and treatment of the genitals;

- Various inflammatory diseases of the oral cavity tongue;

- Immune system disorders (decreased Thelpers)

- AIDS, HIV-like diseases with incomplete diagnosis (with a doctor's recommendation).

For example, an immunobloting method is used that allows the retrovirus to detect antibodies against individual proteins. Once the result obtained by this method is positive, it is possible to draw a conclusion about the incidence of HIV infection.

\section{RESULTS AND DISCUSSION}

On the basis of the project MODEHed "Modernization of medical education in universities" in the framework of the international program ERASMUS + of the European Union, The following results were obtained when comparing the knowledge levels of the groups that taught the basics of valeology "Understanding HIV / AIDS" on the basis of a pre-project model program and then used different methods of transition to the project.

In the 2016-2017 academic year, students intensified and increased their knowledge in the transition to the use of "brainstorming", "presentation", "handouts" in teaching the subject to students.

During the 2017-2018 academic year, the "brainstorming", "presentation", "handouts" as well as the "video" and "case" methods were used to cover the topic of HIV / AIDS. The use of such tools has further increased and intensified student activity.
In the 2018-2019 academic year, the project will cover the topic of "Understanding HIV / AIDS" with the use of "brainstorming", "presentation", "handouts", "case" method, as well as "videos", "animations". Based on the textbook, the topic became the basis for students to increase their knowledge, activity, free thinking on the basis of audio presentations, videos, animation, case method, the use of non-traditional tests.

Comparing the above results, it can be seen that the topic "Understanding HIV / AIDS" has become more active over the years due to the students' ability to freely express their thoughts, explain, analyze and think.

Two months before the subject was taught, students were asked about their HIV status. After the topic was disclosed, the survey was repeated. The results of each survey, that is, the questionnaire, also confirmed the growth of students' knowledge.

In the 2017-2018 academic year, an analysis of a survey of valerology students in the 1st semester revealed that $5-8 \%$ of students did not have a general understanding, $35-40 \%$ heard information from their peers, and 52$60 \%$ read on television and in newspapers.

You can use "brainstorming", presentations, videos, case studies, screenplays, and test assignments at the end of the lesson. Tests are appropriate if they are structured in a nontraditional way, as they show how deeply and completely the student has mastered the topic he or she has mastered.

The lesson should be provided with equipment such as a projector, handouts, computer, paper and pencil, blackboard and chalk. For example, the following test can be used to reinforce a lesson topic.

It is important to give students an understanding of sanitary promotion, stopping the spread of the virus through sex. 
You will learn how to stop the virus from being injected, how to stop the virus from infecting a pregnant woman, and how to fight the virus through blood, blood products, and transplanted organs.

It creates the perception that a sharp knife contaminated with human blood and other fluids can be transmitted from medical devices.

Using the "case method" and grouping in the transition to the topic, moving students into groups as follows will also increase students 'activism and their ability to explain their ideas to others.

For example:

Group 1 parents

Group 2 teachers,

Group 3 doctors

Each group is advised to explain the tasks and find a solution to the problem situation. Each group reads information about the problem situation according to their tasks and tries to find the cause of the problem situation, how it happened, and solve it.

\section{CONCLUSION}

At the same time, students will gain knowledge about AIDS, the causes of the disease, the spread of the disease and ways of transmission, clinical signs of the disease, methods of diagnosis. As a result, the student will gain a deeper understanding of AIDS, the causes of the disease, the spread of the disease, and the routes of transmission. Understands the methods of detecting the first signs of the disease creates skills that increase knowledge.

Thus, the use of ICT and innovative new pedagogical methods, based on our own experience and advanced foreign experience, leads students to become mature professionals in their professional activities, increasing their medical culture, knowledge and skills.

\section{REFERENCES}

1. Yo.Q. Khudoyberdiev. AIDS is a plague of the 2oth century. Tashkent: 2001. p. 7.

2. O.M.Najmiddinov. Acquired Immune Deficiency Syndrome. Tashkent: 1998. -p. 15.

3. R.V. Petrov Immunology. Moscow: 1995. -p. 20.

4. M. Alder. The $A B C$ of AIDS. Moscow: 2002. -p. 10.

5. Joint United Nations Programme on HIV/AIDS (UNAIDS) (2011). Global HIV/AIDS Response, Epidemic update and health sector progress towards universal access. Joint United Nations Programme on HIV/AIDS.

6. Sharipova D.D; Shaxmurova G.A; Khaydarova P; Arbuzova T.D. Prevention of HIV infection among young people. Tashkent: 2009. - p. 28.

7. Kolbanov V.V. Valeological education in primary schools. Primary school. № 4. Moscow: 1999. -p. 32.

8. Safarova D. Valeology. Tashkent: 2006. -p. 196.

9. Sharipova D.D; Shakhmurova G.A; Khaidarova P; Arbuzova T.D. Prevention of HIV infection among young people. Methodological guide for teachers. // headset. Toshkent: 2010. - p. 48.

10. Sharipova D.D; Shakhmurova G.A; Ibragimkhodjaev B.U. Fundamentals of Valeology. Methodical manual for independent study. // headset. Tashkent: 2010. -p. 63. 
